\title{
Ocorrência endofítica de Lasiodiplodia theobromae em tecidos de cajueiro e sua transmissão por propágulos
}

\author{
José Emilson Cardoso ${ }^{1}$, Marlos Alves Bezerra ${ }^{1}$ Francisco Marto Pinto Viana ${ }^{1}$, Tomil Ricardo Maia de Sousa ${ }^{1}$, Alex \\ Queiroz Cysne ${ }^{1}$, Fabio Costa Farias ${ }^{1}$
}

\begin{abstract}
${ }^{1}$ Embrapa Agroindústria Tropical, Rua Dra. Sara Mesquita 2270, CEP 60 511-110, Fortaleza,CE.
Autor para correspondência: José Emilson Cardoso (emilson @ cnpat.embrapa.br.)

Data de chegada: 01/02/2008. Aceito para publicação em: 12/02/2009.
\end{abstract}

\section{RESUMO}

Cardoso, J.E.; Bezerra, M.A.; Viana, F.M.P.; Sousa, T. R. M.; Cysne, A.Q.; Farias, F.C. Ocorrência endofítica de Lasiodiplodia theobromae em tecidos de cajueiro e sua transmissão por propágulos. Summa Phytopathologica, v.35, n.4, p.262-266, 2009

Lasiodiplodia theobromae, agente causal da resinose e da podridão-preta-da-haste é o principal patógeno do cajueiro no semiárido nordestino. Esse patógeno é reconhecido em outros hospedeiros pela capacidade de colonizar tecidos vegetais sem aparente sintoma. Essa característica é de grande importância epidemiológica, prognosticando medidas de exclusão no manejo da doença. A ocorrência epidêmica da resinose em áreas isoladas reforça a hipótese dos propágulos assintomáticos do hospedeiro servirem como fonte de inoculo primário. Os objetivos deste estudo foram determinar a capacidade de L. theobromae de sobreviver em tecidos de cajueiro sem apresentar sintomas e estimar a transmissão deste patógeno via propágulos. A presença do fungo a diferentes distâncias do cancro e nas duas direções em relação ao mesmo (descendente e ascendente) foi determinada pelo plaqueamento de tecidos de troncos infectados. Na outra parte do trabalho, foram coletados em pomares comerciais sementes de plantas sem sintomas e com sintomas severos de resinose. Estas foram semeadas separadamente e as plântulas obtidas foram enxertadas com garfos provenientes de ramos de plantas sadias e ramos de plantas severamente infectadas, perfazendo-se todas as combinações de origem da semente e garfos. As mudas produzidas conforme os quatro tratamentos foram plantadas sob condições favoráveis à doença. L. theobromae foi isolado até $80 \mathrm{~cm}$, tanto na direção ascendente como na descendente em relação do cancro. A interação garfo de planta doente e semente de planta doente apresentou maior incidência da resinose do que a interação garfo de planta sadia e semente de planta doente, mostrando que o garfo também contribui no aumento da incidência.. A interpretação desses resultados evidencia o caráter endofítico de L. theobromae e o propágulo infectado como veículo de introdução da doença no pomar.

Palavras-chave adicionais: resinose, Anacardium occidentale, propagação, epidemiologia.

\section{ABSTRACT}

Cardoso, J.E.; Bezerra, M.A.; Viana, F.M.P.; Sousa, T. R. M.; Cysne, A.Q.; Farias, F.C. Endophyte occurrence of Lasiodiplodia theobromae in cashew tissues and its transmission by vegetative propagules. Summa Phytopathologica, v.35, n.4, p.262-266, 2009

Lasiodiplodia theobromae, agent of gummosis and black branch dieback of cashew, is the most important disease of cashew crop in semi-arid regions of northeastern Brazil. This pathogen is a well known fungus in many host plants as capable of colonizing their tissues without showing disease symptoms. This feature ensures great epidemiologic importance as considering tactics for disease avoidance. The occurrence of cashew gummosis in geographically isolated areas reinforces the seed and scion borne pathogen hypothesis. The objectives of this study were to determine the ability of $L$. theobromae to survive in cashew tissues without showing symptoms and to evaluate plant propagating materials (seed and scion) as source of primary inoculum. The presence of the fungus at different distances from the canker throughout the stem in both ascendant and descendent direction was determined by plating infected tissue samples. In another study, transplanting materials were produced by using rootstocks from seeds sampled either from healthy and gummosis-infected plants and grafted with scions also from healthy and gummosis-infected plants, making a four set of treatments. These plants were transplanted into a commercial cashew farm located in Pio IX, County, Piauí State, highly conducive for disease outbreak. $L$. theobromae was isolated from up to $80 \mathrm{~cm}$ distance from canker in both directions. Greater gummosis incidence was observed in plots initiated by rootstock and scion originated from diseased plants. These findings showed the endophytic behavior of $L$. theobromae in cashew tissues and the importance of rootstock seed as a source of primary inoculum.

Keywords: Gummosis, Anacardium occidentale, grafting, epidemiology.

O potencial sócio-econômico do cultivo do cajueiro no semi-árido é notadamente estratégico, uma vez que se ajusta plenamente ao modelo de exploração conjunta com produtos de subsistência (e.g. feijão-decorda, milho e mandioca) no tempo e no espaço, pois além de fonte de renda, permite a ocupação dos produtores no período de entressafra dessas culturas. Ademais, o desempenho produtivo do cajueiro nas condições do semi-árido é comprovadamente elevado, tanto em quantidade como em qualidade do produto. 
O clima seco e quente contribui para a baixa incidência de doenças fúngicas foliares e proporciona uma maior taxa fotossintética aumentando, consequentemente, o teor de sólidos solúveis no pedúnculo. Entretanto, as doenças causadas por patógenos de plantas submetidas a estresses hídricos são favorecidas por essas condições $(4,5,7)$.

A resinose, causada pelo fungo Lasiodiplodia theobromae, é a principal doença do cajueiro no semi-árido nordestino, observada mais comumente em plantas submetidas a estresses. Os primeiros sintomas da resinose geralmente ocorrem após a primeira safra comercial do cajueiro, cerca de 24 a 36 meses após o plantio (5). Com o progresso da doença, são observados os sintomas característicos, como deficiência nutricional, murcha, queda de folhas, podridão seca dos ramos e a formação de cancros nos ramos lenhosos e no tronco, geralmente acompanhada de exsudação de goma e escurecimento dos tecidos (12). Os danos devido à resinose são decorrentes da redução da produção da planta pelo bloqueio do movimento da seiva nos primeiros estádios de infecção e da produção do pomar pela morte de plantas em virtude da expansão dos cancros (2).

A propagação do cajueiro anão é efetuada predominantemente por meio de mudas, portanto a incidência da resinose em áreas isoladas, em elevadas proporções, suscita a hipótese de transmissão do patógeno por mudas assintomáticas, significando que $L$. theobromae sobreviveria nos tecidos da planta de forma endofítica, podendo o processo infeccioso ser induzido por estresses da planta, principalmente os de ordem fisiológica. O isolamento do fungo de tecidos de cajueiro sadio vem reforçar essa hipótese que, no entanto, necessita ser comprovada.

Fungos endofíticos são aqueles que vivem sistemicamente no interior das plantas sem causar danos, $(9,11,13,16)$. Entretanto, sob condições especiais, alguns desses organismos podem, eventualmente, vir a causar doenças. A ocorrência endofítica de L. theobromae tem sido relatada em outros hospedeiros, sendo o processo de infecção induzido por estresses ambientais que causam o enfraquecimento do hospedeiro $(1,10,14,15,16)$.

A elucidação dos mecanismos de transmissão e a identificação da origem do inóculo primário de $L$. theobromae em cajueiro constituem informações importantes na estratégia de manejo integrado da resinose.

Este trabalho teve como objetivos determinar a capacidade de $L$. theobromae de sobreviver endofiticamente em tecidos de cajueiro e estimar a transmissão da resinose através do enxerto e porta-enxerto de cajueiro.

\section{MATERIAL E MÉTODOS}

\section{Isolamento de $L$. theobromae de tecidos de cajueiro}

Amostras de ramos lenhosos de cajueiro apresentando cancros característicos da resinose foram coletadas e levadas para o Laboratório de Fitopatologia da Embrapa Agroindústria Tropical. Inicialmente, esses ramos foram lavados com água corrente e desinfestados superficialmente com etanol $(70 \%)$ e hipoclorito de sódio (3\% de cloro), e então lavados com água destilada esterilizada. Após a desinfestação, da região do lenho de cada ramo, foram retirados de logo abaixo da casca, a partir do centro do cancro, 20 fragmentos (1-2 $\mathrm{mm}$ ) distando de $10 \mathrm{~cm}$ entre si até o máximo de $80 \mathrm{~cm}$ do centro da lesão. As amostras foram retiradas no sentido ascendentes e colocadas em meio de ágar - água ( $10 \%$ ágar) contido em quatro placas de Petri ( 9 $\mathrm{cm}$ de diâmetro). Após uma semana de incubação à $28^{\circ} \mathrm{C}$, as hifas emergentes semelhantes às de L. theobromae foram transferidas para placas contendo meio batata-dextrose-ágar (BDA) para posterior confirmação. A percentagem de fragmentos que geraram colônias de $L$. theobromae foi estimada.

Um segundo ensaio, foi realizado utilizando a mesma metodologia do primeiro, porém com as amostras dos fragmentos de ramos retirados nos sentidos ascendente e descendente em relação ao cancro. As distâncias de onde se coletou os fragmentos variaram de 0 à $90 \mathrm{~cm}$ retiradas a cada $10 \mathrm{~cm}$.

Visando confirmar a sobrevivência do fungo em tecidos de cajueiro sem sintomas da resinose, realizou-se um terceiro ensaio, em que amostras de ramos e troncos de 30 cajueiros, com e sem sintomas de resinose, provenientes de diversos municípios do Nordeste foram coletados e levados para o laboratório. A exemplo do procedimento anteriormente descrito, fragmentos retirados desses materiais foram plaqueados em meio ágar-água, incubados em laboratório sob temperatura de $28^{\circ} \mathrm{C}$ e monitorados quanto ao desenvolvimento de colônias de L. theobromae.

Efeito da origem do propágulo na ocorrência da resinose

Amostras de frutos de cajueiro do clone CCP 76 provenientes de plantas sem sintomas e com sintomas severos de resinose foram coletadas em dois pomares comerciais na região semi-árida. As plântulas obtidas dessas sementes foram enxertadas com garfos provenientes de ramos de plantas sadias e severamente atacadas, perfazendo-se assim as seguintes combinações: $1=$ semente de planta sadia e garfo de planta sadia $(\mathrm{SS}+\mathrm{GS}), 2$ = semente de planta sadia e garfo de planta doente $(\mathrm{SS}+\mathrm{GD}), 3=$ semente de planta doente e garfo de planta sadia $(\mathrm{SD}+\mathrm{GS})$ e $4=$ semente de planta doente e garfo de planta doente (SD $+\mathrm{GD})$.

As mudas foram transplantadas para uma área na Fazenda Planalto, localizada no município de Pio IX, PI (Latitude 6 31' 30S, Longitude $40^{\circ} 47^{\prime} 19 \mathrm{~W}$, Altitude $605 \mathrm{~m}$ ). As características do clima na região onde está situada a fazenda é de temperatura média de $24^{\circ} \mathrm{C}$, umidade relativa do ar em torno de $60 \%$ e pluviosidade média de $700 \mathrm{~mm}$. O solo da área do experimento é do tipo LATOSSOLO Amarelo Álico com $\mathrm{pH}$ de 4,5.

\section{Análise Estatística}

O delineamento experimental empregado foi o de blocos ao acaso com cinco repetições, disposto em esquema fatorial $2 \times 2$, sendo os fatores a origem da semente e a origem do garfo. Cada parcela constou de seis plantas. $O$ modelo experimental foi $Y=\grave{i}+S_{i}+G_{j}+S_{i j}+B_{K}$ $+E_{i j k}$, onde $Y=$ resinose, $\grave{i}=$ média, $S_{i}=$ efeito devido à origem da semente, $\mathrm{G}_{\mathrm{j}}=$ efeito devido à origem do garfo, $\mathrm{SG}_{\mathrm{ij}}=$ efeito devido a interação da origem da semente com a origem do garfo, $\mathrm{B}_{\mathrm{K}}=$ efeito devido ao bloco e $E_{i j k}=$ erro experimental. A ocorrência da resinose foi monitorada trimestralmente durante 36 meses.

\section{RESULTADOS E DISCUSSÃO}

\section{Isolamento de $L$. theobromae de tecidos de cajueiro}

No primeiro ensaio, $L$. theobromae foi isolado de fragmentos de tecidos do tronco do cajueiro ao longo de 9 diferentes distâncias em relação ao cancro na direção ascendente, (do cancro à $80 \mathrm{~cm}$ ). A maior percentagem de isolamento foi observada no centro do cancro, conforme esperado, Esta percentagem atingiu em média 50\% de colônias obtidas nas quatro repetições. No restante dos fragmentos coletados nas outras distâncias de 10 a $80 \mathrm{~cm}$ foi observada uma 


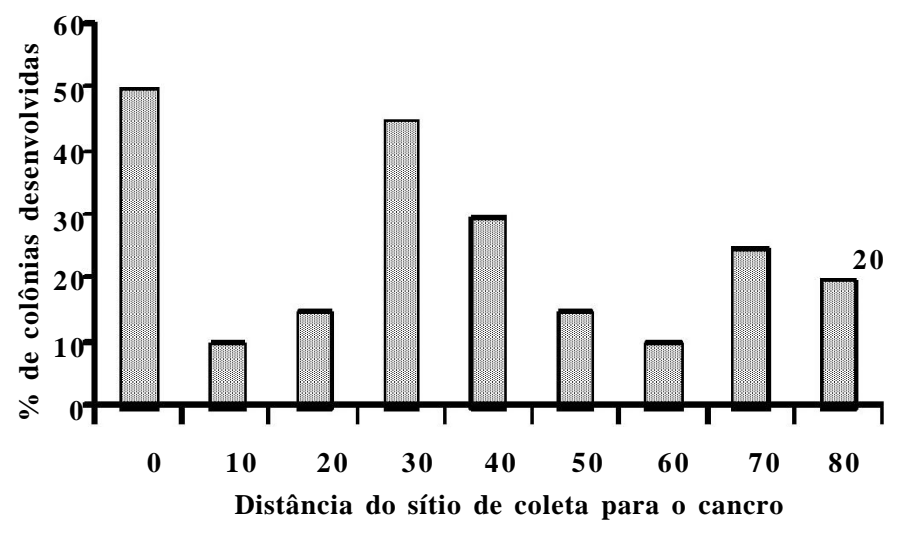

Figura 1. Porcentagem de colônias de Lasiodiplodia theobromae, desenvolvidas em BDA, a partir de tecidos de cajueiro conforme a distancia do cancro (ponto zero). Os dados representam médias de quatro repetições.

variação na porcentagem de colônias de 10 a $45 \%$ à medida que a distância aumentava. (Figura 1). Esperava-se que o número de colônias desenvolvidas fosse decrescente em relação à distancia do cancro, o que não ocorreu. A pouca uniformidade no tamanho das amostras e na localização do fragmento plaqueado pode ser responsável por essa irregularidade. Pois a escolha do sitio de retirada do fragmento foi feita com base em medidas (i.e. $10 \mathrm{~cm}$ ) não tendo sido considerado o tipo de tecido (i.e. gema ou internódio).

No segundo ensaio, L. theobromae foi isolado até $90 \mathrm{~cm}$ em ambas os sentidos (i.e. ascendente ou descendente, em relação ao cancro), embora as proporções de isolamento obtidas se mostraram irregulares, não apresentando o esperado padrão decrescente em relação ao cancro, a exemplo do ensaio anterior (Figura 2). Diferentemente dos dados anteriores, as proporções de isolamentos a partir dos cancros (i.e. distancia zero) foram menores (20\%) em relação às outras distancias, provavelmente porque os tecidos já se encontravam em estádios avançados de necrose, conseqüentemente com maior população de microrganismos oportunistas que suprimiram o crescimento de $L$. theobromae. Nas demais distâncias avaliadas, foram observadas irregularidades quanto à proporção de colônias, a exemplo do ensaio anterior. Entretanto, estes dados confirmam o comportamento endofítico de L. theobromae também em troncos de cajueiro (Figura 2). O termo endofitico, porém, tem sido muito discutido em relação

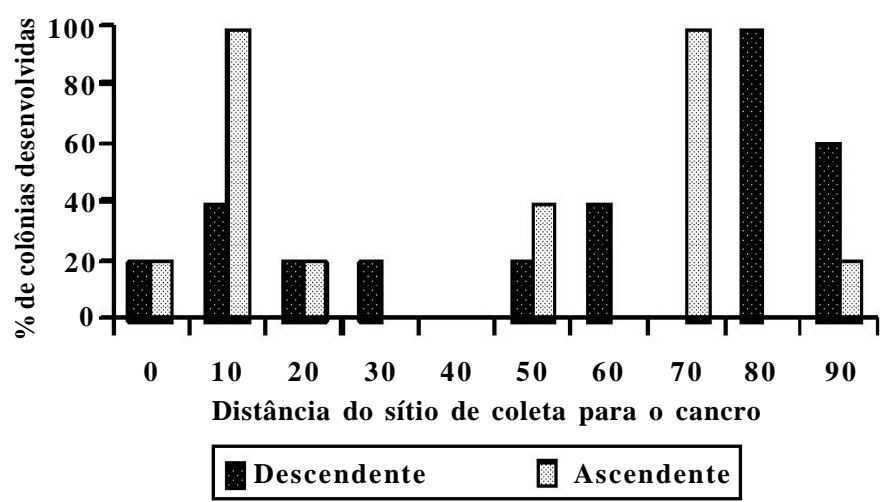

Figura 2. Porcentagem de crescimento micelial de Lasiodiplodia theobromae, desenvolvidas em BDA, a partir de tecidos de cajueiro conforme a distancia (ponto zero) e o sentido (descendente e ascendente) em relação ao cancro. aos organismos considerados patógenos latentes, como na família Botryosphaeriaceae da qual L. theobromae pertence (17).

No terceiro ensaio, 25 colônias (11 isoladas de amostras com sintomas e 14 de amostras sem sintoma de ramos e troncos de cajueiro) de $L$. theobromae foram obtidas das 30 amostras de tecido de cajueiro de vários municípios do Nordeste, sendo que 12 apresentavam sintomas característicos da resinose (cancro) enquanto 18 amostras não apresentavam sintomas. Aproximadamente $92 \%$ dos fragmentos de tecidos com sintomas e $78 \%$ dos fragmentos de tecidos sem sintomas, produziram colônias do fungo, revelando a capacidade de $L$. theobromae de sobreviver naturalmente em tecidos assintomáticos de cajueiro (Tabela 1). Estes dados podem ser interpretados segundo duas perspectivas distintas. Uma refere-se ao caráter essencialmente endofitico do fungo, definido pela característica mutualística da relação com o hospedeiro (17), enquanto que, a outra sugere o caráter de patógeno latente. Estudos sobre a estrutura genética da população do fungo e as interações fisiológicas entre ecotipos e com o hospedeiro poderão contribuir para a elucidação dessas questões.

No presente estudo, o comportamento endofítico de L. theobromae foi confirmado, conforme suposições anteriores baseadas em observações em outras espécies $(14,15,16,17)$. Esta informação revestese de uma importância marcante no delineamento de estratégias de manejo da resinose, sendo, por conseguinte muito mais difícil o uso eficiente de medidas de exclusão. O grande número de espécies hospedeiras e a aparente falta de especialização por hospedeiro aliado

Tabela 1. Tipo de cajueiro amostrado, localização das plantas e presença ou ausência de sintomas da resinose que produziram colônias de Lasiodiplodia theobromae, Fortaleza, CE. 2007.

\begin{tabular}{|c|c|c|}
\hline Tipo ou clone & Local & Sintoma ${ }^{1}$ \\
\hline Comum & Pacajus, CE & + \\
\hline Comum & Beberibe, CE & + \\
\hline Comum & Alto Santo, CE & + \\
\hline Comum & Quixeré, CE & + \\
\hline Comum & Crato, $\mathrm{CE}$ & - \\
\hline Comum & Palmácia, CE & - \\
\hline Comum & Iguatu, CE & - \\
\hline Comum & Trairi, CE & + \\
\hline Comum & Itapipoca,CE & - \\
\hline Comum & Marco, CE & - \\
\hline Comum & Jijoca - Estrada Cruz, CE & - \\
\hline Comum & Jijoca - Lagoa, CE & - \\
\hline Clone, CCP 76 & Camocim, CE & - \\
\hline Comum & Ipu - Sr. Bráulio, CE & - \\
\hline Comum & Ipu - Sitio Minas, CE & - \\
\hline Clone, CCP 76 & Hidrolândia, CE & - \\
\hline Comum & Oeiras, PI & + \\
\hline Comum & Floriano, PI & + \\
\hline Clone, CCP 76 & Floriano, PI & + \\
\hline Clone, CCP 76 & São Raimundo Nonato, PI & + \\
\hline Comum & Parnaíba, PI & - \\
\hline Comum & Severiano Melo, RN & + \\
\hline Comum & Serra do Mel, RN & - \\
\hline Comum & Cajazeiras, PB & + \\
\hline Clone, CAP 14 & Petrolina, PE & - \\
\hline
\end{tabular}

Sintomática (+); Assintomática (-). 
ao caráter endofítico de $L$. theobromae certamente impõe grandes obstáculos ao controle de doenças causadas por esse organismo. Estudos genéticos baseados em marcadores de DNA objetivando identificar e caracterizar as populações prevalecentes nos diferentes tecidos, hospedeiros e localização geográfica tornam-se cada vez mais necessários na elucidação dos mecanismos de interação com as plantas cultivadas $(8,14,17)$.

Efeito da origem do garfo e semente na ocorrência da resinose

A primeira ocorrência de resinose no campo foi detectada quando as plantas estavam com dez meses de idade, comprovando estudos anteriores (5). Uma maior incidência de resinose foi observada nas plantas produzidas de sementes de plantas que apresentavam sintomas, independente da sanidade do enxerto (Figura 3). A análise de variância e os níveis de incidência de resinose apresentaram uma diferença significativa do teste $\mathrm{F}$ (valor de $\mathrm{P}=0,0295$ ) considerando o fator origem da semente (Figura 3 ).

O isolamento de L. theobromae sempre foi possível a partir de tecidos lenhosos de cajueiro, contrastando com um diferente ecotipo, geneticamente distinto, que infecta tecidos não lenhosos, descrito como o agente de uma outra doença do cajueiro chamada podridãopreta-da-haste (8).

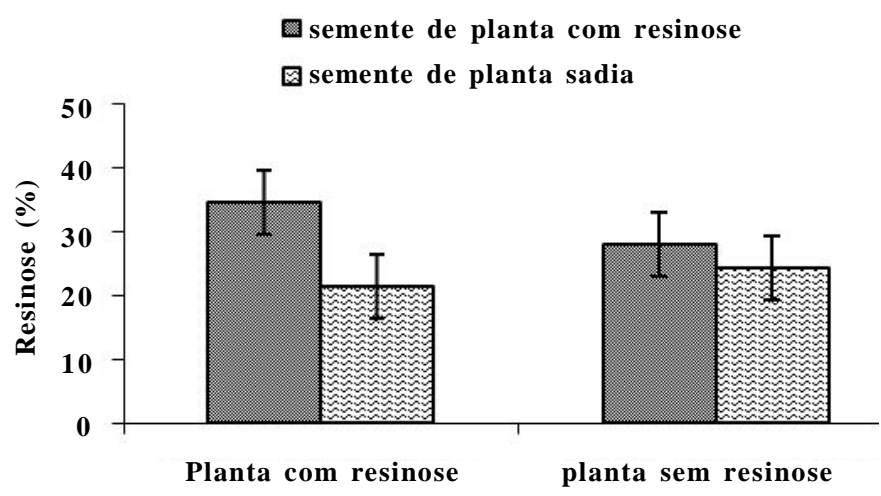

Origem do garfo

Figura 3. Porcentagem de incidência de resinose, comparando garfo e semente originários de plantas com e sem resinose. Dados são médias de cinco repetições de seis plantas cada, após 36 meses de plantio no campo.
A análise de variância dos resultados revelou uma interação significativa entre os fatores origem da semente e do garfo, sugerindo o desmembramento visando verificar o efeito de cada componente da interação. Foi observado que a interação garfo de planta doente e semente de planta doente apresentou valores bem mais elevados do que a interação garfo de planta sadia e semente de planta doente, mostrando que o garfo também contribui no aumento da incidência, embora a origem do garfo não tenha sido significativa para a incidência da resinose (Figura 3). Neste caso, o efeito pode ser indireto, ou seja, o garfo de planta doente contribui mais pelo menor vigor ou maior sensibilidade ao estresse da planta.

A análise da interação entre origem da semente e do garfo revela que a interação de semente e garfo originados de plantas sem sintoma não apresentou diferença significativa de valores de incidência para as outras interações, aproximadamente $25 \%$, exceto a interação que semente e garfo são originados de plantas com sintomas da doença, cerca de $35 \%$, com nível de significância nominal do teste $\mathrm{F}$ com valor de $\mathrm{P}=0,018$, indicando que a origem da semente tem um efeito mais marcante na ocorrência da doença. A ocorrência da resinose em quase todas as plantas ao longo dos 36 meses de monitoramento revelou que, apesar da importância da muda (origem da semente e do garfo) representar um aspecto importante na incidência da doença, outros agentes de disseminação (e.g. artrópodes, pássaros e podas) $(3,6)$ são importantes nas áreas onde a doença já está estabelecida (Figura 4).

A resinose tem sido descrita como uma doença que se inicia quando as plantas já se encontram com idade igual ou superior a 18 meses, coincidindo com o início da produção comercial. Como o plantio é feito no inicio da estação chuvosa, o cajueiro terá sua primeira floração e produção concentrada justamente no período seco do ano, conseqüentemente mais vulnerável ao estresse hídrico. Essa assertiva pode ser confirmada pelos dados obtidos nesse estudo. A análise do progresso da resinose considerando-se o fator origem da semente revela que, do décimo até o décimo sétimo mês, não foi observado nenhuma diferença significativa para esses fatores, fato que sugere a presença de outros agentes de disseminação do patógeno. Entretanto, à medida que a epidemia progrediu observou-se uma maior incidência nas plantas originadas de sementes provenientes de plantas doentes (Figura 4), evidenciando-se claramente a importância da semente no progresso da resinose, sobretudo na fase de maior taxa de crescimento da doença $(i$.

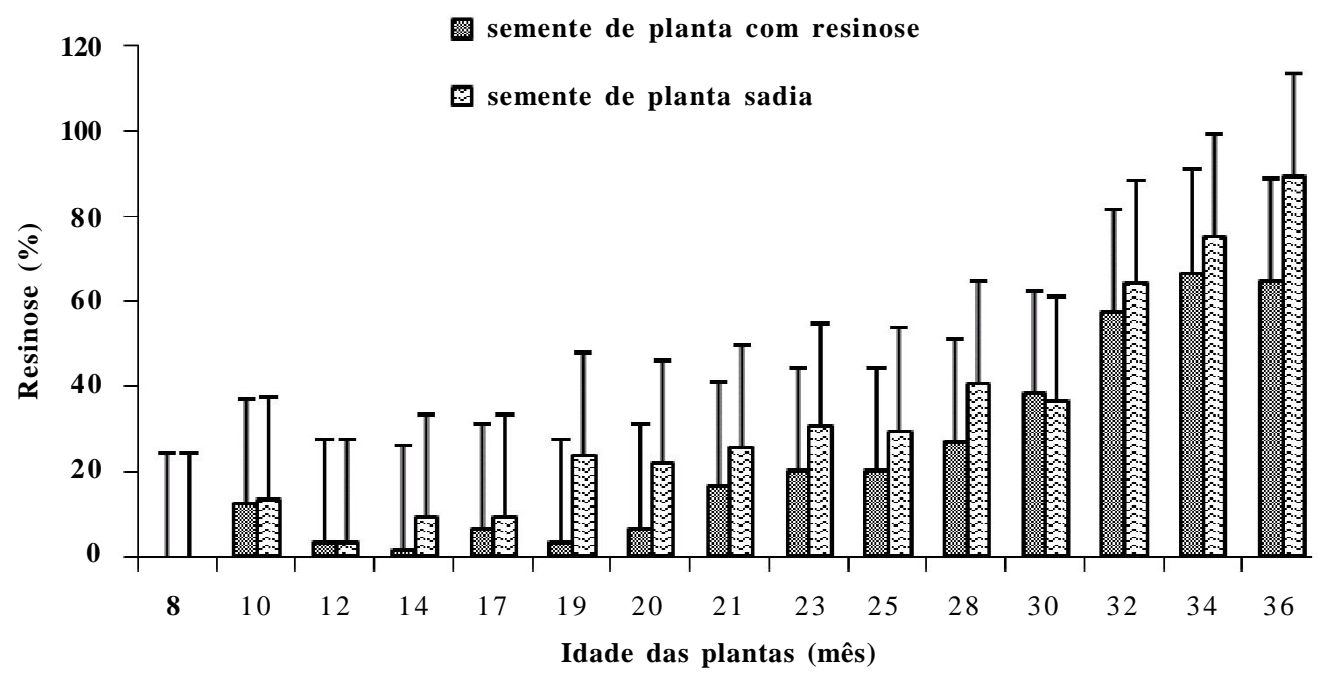

Figura 4. Progresso da resinose em todo o experimento (A) e comparação das médias de incidência resinose quanto ao fator origem da semente: semente sadia $=$ plantas originárias de sementes de plantas sem resinose e semente doente= originárias de sementes de plantas com resinose $(B)$. 
e. 18 a 25 meses).

As informações obtidas neste trabalho permitem comprovar a capacidade de L. theobromae de sobreviver internamente nos tecidos de cajueiro, sem causar nenhum sintoma, além de estabelecer a importância relativa da origem da semente e do garfo na disseminação primária da resinose. Estudos posteriores sobre as interações entre os ecotipos presumivelmente endofiticos e o hospedeiro são necessários a fim de avaliar o potencial de utilização desses organismos como agentes de controle biológico da resinose, a exemplo de outras interações $(11,16)$.

\section{REFERÊNCIAS BIBLIOGRÁFICAS}

1. Baird, R.; Carling, D. Survival of parasitic anal saprophytic fungi or intact senescent cotton roots. The Journal of Cotton Science, Cordova, Tennessee. USA. v.2, p. 27-34, 1998.

2. Bezerra, M.A.; Cardoso, J.E.; Santos, A.A.; Vidal, J.C.; Alencar, E.S. Efeito da Resinose na Fotossíntese do Cajueiro-Anão Precoce. Fortaleza: Embrapa Agroindústria Tropical, 2003, (Boletim de Pesquisa e Desenvolvimento, 8).

3. Cardoso, J.E.; Freire, F.C.O. Identificação e manejo das principais doenças. In: Melo, Q.M.S. (Org.). Caju-Fitossanidade. Brasília, DF: Embrapa Informação Tecnológica, 2002. p. 41-51.

4. Cardoso, J.E.; Freire, F.C.O.; SÁ, F.T. Disseminação e controle da resinose em troncos de cajueiro decepados para substituição de copa. Fitopatologia Brasileira, Brasília, DF, v. 23, n. 1, p. 4850, 1998 .

5. Cardoso, J.E.; Paiva, J.R.; Cavalcanti, J.J.V.; Santos, A.A.; Vidal, J.C. Evaluation of resistance in dwarf cashew to gummosis in north-eastern Brasil. Crop Protection, London, v. 25, p. 855859. 2006.

6. Cardoso, J.E.; Vidal, J.C.; Santos, A.A.; Freire, F.C.O.; Viana, F.M.P. First report of black branch dieback of cashew caused by Lasiodiplodia theobromae in Brasil. Plant Disease, St. Paul, MN, v. 86, n. 5, p. 558, 2002.
7. Cardoso, J.E.; Vidal, J.C.; Uchoa, C.N.; Alencar, E.S.; Silva, R.C. Diagnóstico do sistema produtivo do cajueiro no sudeste do Piauí. Fortaleza, Embrapa Agroindústria Tropical, 2003, (Comunicado técnico, 83).

8. Cardoso, J.E.; Wilkinson, M.J. Development and characterisation of microsatellite markers for the fungus Lasiodiplodia theobromae. Summa Phytopathologica, Botucatu, v. 34, n. 1, p. 55-57. 2008.

9. Carroll G.C. Fungal endophytes in stems and leaves: from latent pathogen to mutualistic symbiont. Ecology, Ithaca, v. 69, p. 2 9, 1998.

10. Cilliers, A.A review of Lasiodiplodia theobromae with particular reference to its occurrence on coniferous seeds. South African Forest Journal. Pretoria, v. 166, p. 47-52, 1993.

11. Faeth, S.H. Are endophytic fungi defensive plant mutualists? OIKOS, Lund, v. 98, p. 25-36, 2002.

12. Freire, F.C.O.; Cardoso, J.E.; Santos, A.A.; Viana, F.M.P. Diseases of cashew (Anacardium occidentale L.) in Brazil. Crop Protection, v. 21, London, p. 489-494, 2002.

13. Microrganismos endofíticos. Jornal do Endofítico. Disponível em na rede mundial de computadores: Acesso em: 30 jan. 2008.

14. Mohali, S.; Burgess, T.I.; Wingfield, M.J. Diversity and host association of the tropical tree endophyte Lasiodiplodia theobromae revealed using simple sequence repeat markers. Forest Pathology, Blackwell Verlag, Berlin, v. 35, p. 385-396, 2005.

15. Mullen, J.M.; Gilliam, C.H.; Hagan, A. K.; Morgan-Jones, G. Canker of dogwood caused by Lasiodiplodia theobromae, a disease influenced stress or cultivar selection. Plant Disease, St. Paul, v.75, p. 886-889, 1991.

16. Rubini, M.R.; Silva-Ribeiro, R.T.; Pomella, A.W.V.; Maki, C. S.; Araújo, W. L.; Santos, D. R. D.; Azevedo, J. L. Diversity of endophytic fungal community of cacao (Theobroma cacao L.) and biological control of Crinipellis perniciosa, causal agent of Witches' Broom Disease. International Journal of Biological Sciences, New South Wales, v. 1, p. 24-33, 2005.

17. Slippers, B.; Wingfield, M.J. Botryosphaeriaceae as endophytes and latent pathogens of woody plants: diversity, ecology and impact. Fungal Biology Reviews, Amsterdam, v. 21, p. 90-106, 2007. 